\title{
Conference Paper \\ Surface Analysis of Chain Joint Components after Tribological Load and Usage of Antiwear Additives
}

\author{
D. Sappok, ${ }^{1}$ R. Merz, ${ }^{2}$ B. Sauer, ${ }^{1}$ and M. Kopnarski ${ }^{2}$ \\ ${ }^{1}$ Institute of Machine Elements, Gears, and Transmissions (MEGT), University of Kaiserslautern, 67663 Kaiserslautern, Germany \\ ${ }^{2}$ Institute for Surface and Thin Film Analysis (IFOS), 67663 Kaiserslautern, Germany \\ Correspondence should be addressed to D. Sappok; daniel.sappok@mv.uni-kl.de
}

Received 31 July 2014; Accepted 10 September 2014

Academic Editor: Martin Dienwiebel

This Conference Paper is based on a presentation given by D. Sappok at "European Symposium on Friction, Wear, and Wear Protection" held from 6 May 2014 to 8 May 2014 in Karlsruhe, Germany.

Copyright (C) 2015 D. Sappok et al. This is an open access article distributed under the Creative Commons Attribution License, which permits unrestricted use, distribution, and reproduction in any medium, provided the original work is properly cited.

\begin{abstract}
Wear in chain joints leads to an increased clearance and thus an elongation of the entire chain which determines the lifetime of the chain. This particularly applies for chains that are used in timing chain drives. The aim of this study was to investigate especially the influences of lubricant additives and a contamination with carbon black on the tribological behavior of chain joint components and to correlate these influences to observable changes in topographical and chemical surface properties. A precisely defined contact and load situation is essential for generating a comparable series of samples for surface analyses. To meet this requirement, chain joint component samples from tests on a linear reciprocating model tribometer were used for the following analyses. But to connect the results to the realistic situation regarding the typical wear rates of the subjected chain types, suited experimental parameters were selected. Topographical, structural, and chemical characterization of the worn surface regions of the components were performed after the tribological loading. The results show the influence of the lubricant, the additive, and the contamination with carbon black especially on the chemical properties of the component surfaces.
\end{abstract}

\section{Introduction}

The chain joint, which consists of a pin and a bush, is a very critical part as far as wear and energy efficiency are concerned. The joint wear of driving chains determines their lifetime. In an operating chain drive, the chain is loaded with a driving torque that leads to the contact forces within the chain joints. When the chain runs onto and off the sprocket, the two parts of the chain joints, bush and pin, perform a relative motion. The same occurs if there are vibrations in the slack strand of the chain drive. Due to the contact forces and the sliding motion, the pin and the bush of the chain joints are worn out at a certain area which is shown in Figure 1. The clearance of the joints is increased and this leads to an elongation of the entire chain. Furthermore, the friction losses within the chain joint determine to a great extent the energy efficiency of the entire chain [1].
Reducing wear and improving the energy efficiency are often the goal of product enhancements. This especially accounts for the automotive industry. The performance of an entire engine is determined by the performance of every single component. Therefore the improvement of the energy efficiency and the wear behavior of chains that are used in timing chain drives in combustion engines are of high interest. To achieve this goal, one approach is to optimize the surface of the contacting bodies, in this case the surfaces of pin and bush [1].

For these optimizations, it is necessary to fully understand the wear mechanisms in the chain joint. To investigate the wear mechanisms and to measure the influence of surface modifications on the wear, chain test rigs are used which allow for operating chains with well-defined operating conditions. These conditions are chosen to be very close to the actual loads in the combustion engine [2-4]. 


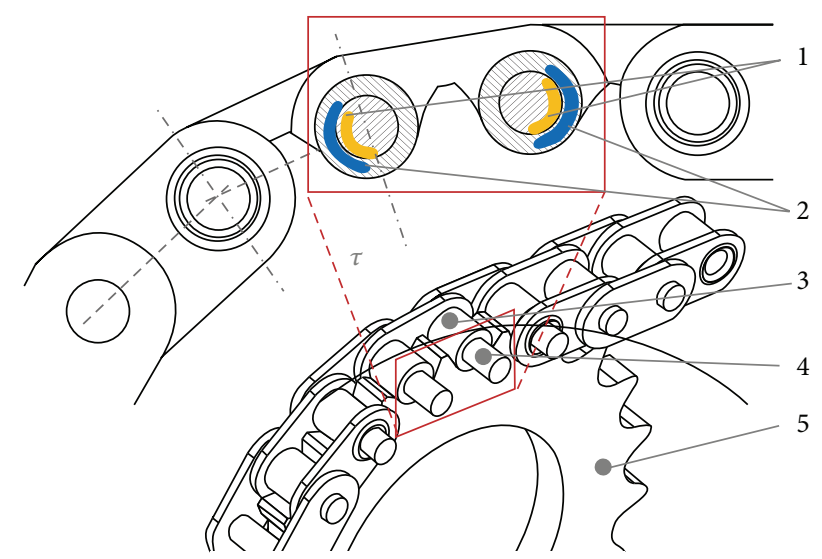

FIGURE 1: Areas of wear in bush chain joints (1: wear areas on pin; 2: wear areas on bush; 3: bush; 4: pin; 5: sprocket).

Unfortunately, these test rig investigations are very complex and time consuming. A large number of modified components are necessary to build up a chain and the setup of the test rig and the accompanying wear measurements are costly in terms of time. An alternative approach to evaluate the tribological behavior of machine components is the tribometer test. One standard tribometer setup is the pin-on-disc type. In this type, usually a ball on a pin is pressed against a flat surface which rotates (Figure 2(a)) or reciprocates linearly (Figure 2(b)).

\section{Wear Investigations on Chains}

2.1. Experimental Investigations. To conduct wear investigations with operating conditions that are very close to the real situation in the application of the chain, a wear test rig is used (Figures 3(a)-3(b)). The test rig for chain drives can be used for different types of chains such as roller, bush, and silent chains. Furthermore, the wear or the energy efficiency can be of interest for the investigation. To allow for this wide range of chain types and different tasks, the test rig is designed to be as modular as possible $[4,6]$.

The wear that occurs during the operation is measured with different methods. For example, a length measurement unit and a clearance and stiffness measurement device are used (Figure 4(a)). With both devices, the wear elongation over the operating time of the chain is obtained in which the running in wear during the first hours and the steady-state wear can be seen [6]. The wear elongation curves for Chain 1 and Chain 2 were obtained with the same type of chains but with different types of lubricant. The tested chains are bush chains with a pitch of $8 \mathrm{~mm}$. For Chain 1 a poly-alphaolefin (PAO) with antiwear additives was used and the oil was contaminated with $1 \mathrm{wt} \%$ of carbon black to simulate the presence of soot in a real engine. For Chain 2, the same PAO was used without carbon black.

By using a roundness measuring instrument, the inner contour of the bush and the contour of the pin are measured (Figure $4(\mathrm{~b})$ ). The advantage of this method is that the wear volume in a single chain joint can be evaluated and the distribution of the wear between pin and bush can be obtained [6]. Furthermore, this method is used to measure the contour of the bush as input data for a wear calculation model which is presented in the following chapter.

2.2. Simulation and Calculation. To complement the experimental methods presented above, simulations are conducted to calculate the inner loads in a chain joint and the wear progress itself. In order to calculate wear, a model has been developed at the MEGT. The contact between pin and bush is calculated analytically which includes the evaluation of the bending line of the pin. The bending line depends on the inner contour of the bush and the force distribution along the axis of the pin which are both taken into account in this calculation. With these results, the contact pressure distribution can be computed. The principle of this calculation model is shown in Figure 5.

In the next step, a wear calculation approach is used. A commonly used approach is the one developed by Archard. This approach is modified to take the contact area into account. Additionally, a nonlinear influence of the contact force is assumed [9] which leads to the following equation:

$$
V=K \cdot\left(\frac{F}{A}\right)^{m} \cdot s .
$$

With the calculated wear volume $V$, the new contact geometry can be computed. The quality of these results critically depends on the contact pressure distribution and the correctness of the load input data. To verify the contact pressure distribution a finite-element model was built up in Abaqus and the results of the wear calculation were compared to the FE simulation which showed a good correlation $[7,8]$. One limitation of this tool is that the wear volume and thus a change of the contour are completely applied to the bush. This assumption is valid for some chain types, depending on the type of materials and the surface treatment of pin and bush but it has to be taken into account for chains where material is removed from both pin and bush during the operation. More details of the wear calculation model can be found in $[7,8,10]$.

The calculation tool is used to compute the pressure distribution and the change of the inner contour of the bush for Chain 1 and Chain 2 (Figure 4(b)). As the wear volume is calculated as well, the volumetric wear coefficient which can be used to compare tribological systems can be computed continuously for both wear elongation curves. These results are shown in Figure 6.

Figure 6(a) shows the pressure distribution for one half of the bush for different bush contours and different wear states, calculated with the wear calculation tool. With a new cylindrical contour, the maximum pressure is $530 \mathrm{MPa}$ which is reduced to $410 \mathrm{MPa}$ when choosing a contour that is derived from measurements of the real contour of bushes. In the steady-state wear area after $100 \mathrm{~h}$ operating time, the contact pressure is almost evenly distributed over the bush axis and the maximum contact pressure is $130-140 \mathrm{MPa}$ for both cylindrical and real contour. The volumetric wear coefficient for Chain 1 is of $10-20 \times 10^{-8} \mathrm{~mm}^{3} / \mathrm{Nm}$ and for Chain 2 of $0.8-8 \times 10^{-8} \mathrm{~mm}^{3} / \mathrm{Nm}$. 


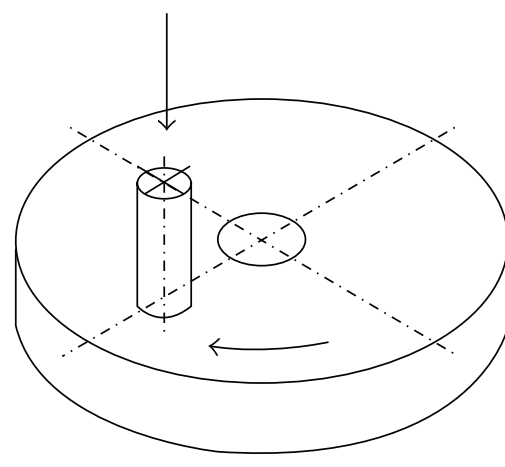

(a)

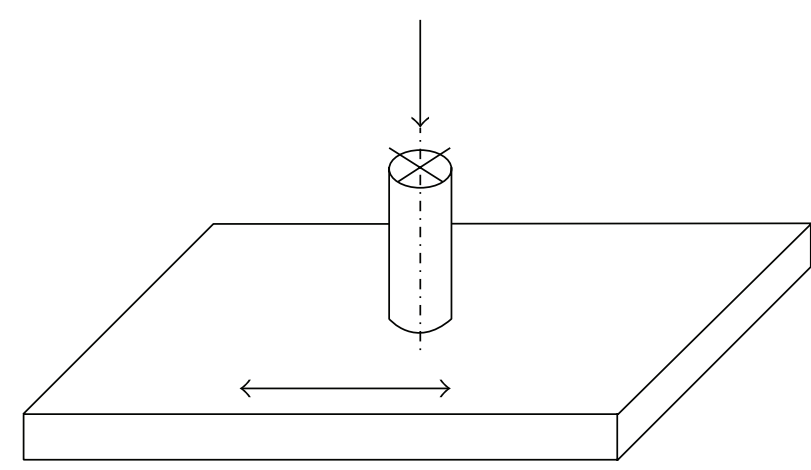

(b)

FIGURE 2: Pin-on-disc operating modes: (a) rotating [5], (b) linearly reciprocating.

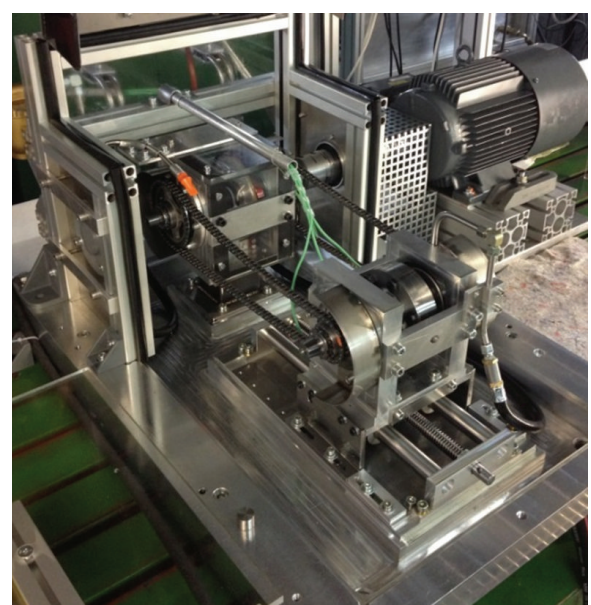

(a)

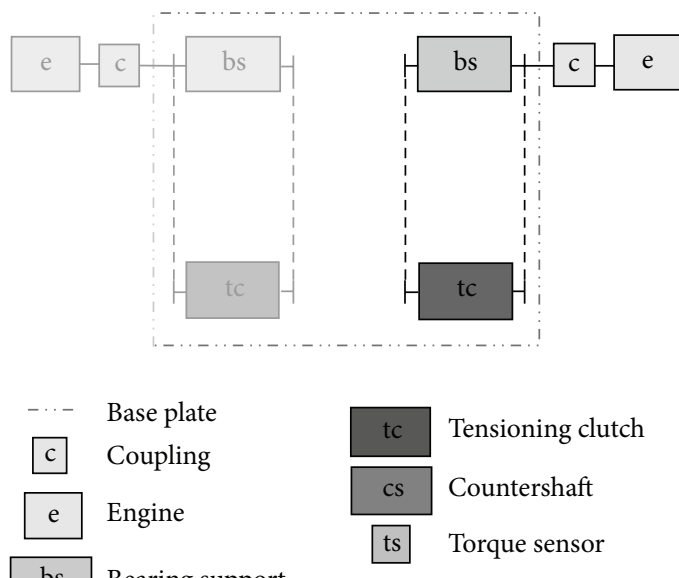

(b)

FIGURE 3: Experimental wear investigations: (a) wear test rig; (b) schematic representation of the test rig showing the setup for wear investigations.

With the above described methods, whole chains can be tested with conditions that are very close to the real situation in a combustion engine, for example. But there are some drawbacks. First, the investigations with the wear test rig are costly in terms of time. Second, the load conditions in one single chain joint are not known exactly as they are influenced by manufacturing tolerances, for example, of the chains pitch and the roundness of the sprockets. The third drawback is that the contact areas are not easily accessible when the surface has to be analyzed in detail, for example, regarding the surface structure or the chemical composition of the surface. To overcome these drawbacks, standard tribometer experiments are used to complement the wear test rig investigations, which is described in the following chapters.

\section{Model Tribometer Tests with Chain Components}

When conducting model tribometer experiments it is of great importance to choose a setup in which the contact situation and the load conditions of the tribological contact are as close as possible to the ones in the real application. Other very important issues are the components used for the tribometer tests. If these components have to be purpose made for the tribometer, there is always a very high influence of the manufacturing process because the batch production process is usually different from preproduction processes. The best solution for this requirement is to take the components for the tribometer tests directly from the batch production with as few modifications as possible.

In the chain joint the normal load and the contact area are comparatively high which makes it difficult to resemble this situation on the tribometer. To get as close as possible to the real contact situation by using the components from the batch production, a setup where the outside of the bush is pressed against the pin and the pin reciprocates linearly is used (Figure 7).

Both pin and bush are case hardened. The surface properties on the inside of the bush were compared to the ones on the outside. The hardness and the case hardening depth are the same but the roughness values $R_{a}$ are slightly higher 

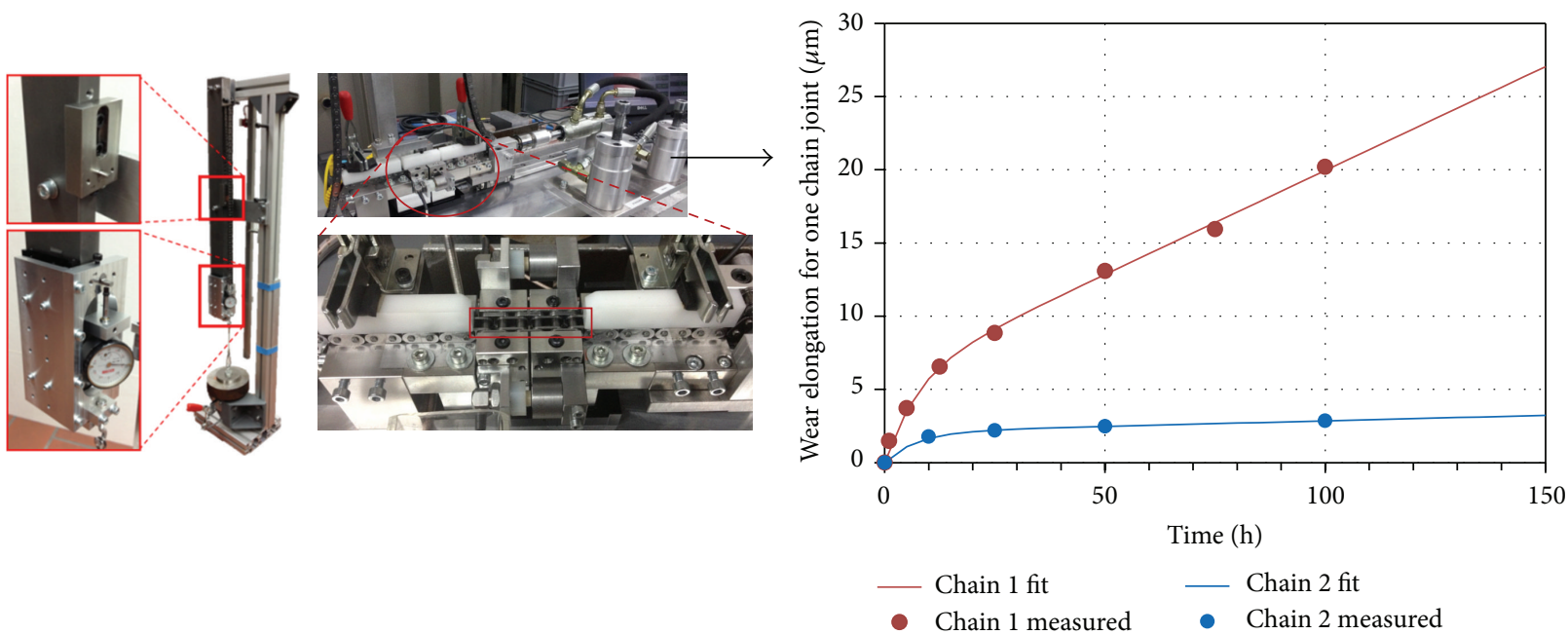

(a) Length, clearance, and stiffness
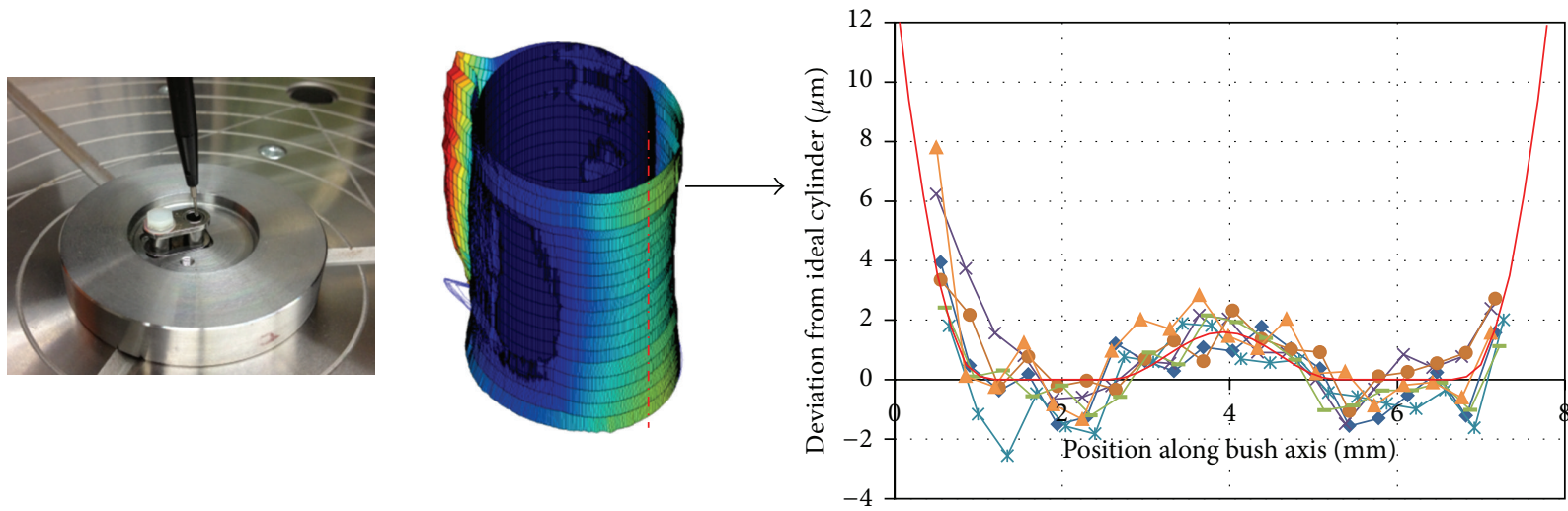

(b) Contour of pin and bush

Figure 4: Wear measurement: (a) length, clearance, and stiffness measurement devices to obtain the wear elongation; (b) contour measurement of pin and bush.

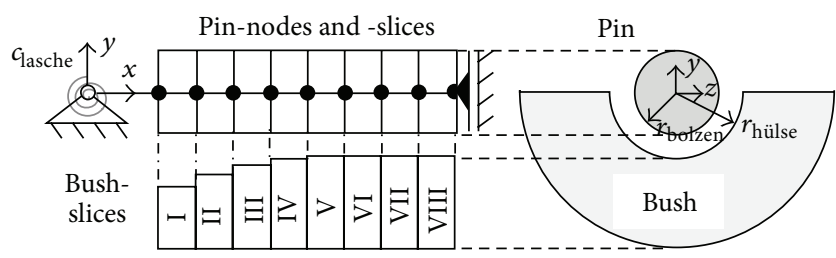

FIgURE 5: Calculation of the contact pressure [7].

TABLE 1: Properties of the test samples.

\begin{tabular}{lcc}
\hline Property & Pin & Bush \\
\hline Material & $16 \mathrm{MnCr} 5$ & $10 \mathrm{NiCr} 5-4$ \\
Surface treatment & Case hardened & Case hardened \\
Hardness (surface) & $883 \pm 30 \mathrm{HV} 0.01$ & $922 \pm 22 \mathrm{HV} 0.01$ \\
Roughness $R_{a}$ & $0,08 \pm 0,01 \mu \mathrm{m}$ & $0,35 \pm 0,05 \mu \mathrm{m}$ \\
\hline
\end{tabular}

for the inside surface. The materials and the hardness values of the tested chain components, pin and bush, are shown in Table 1 .
TABLE 2: Comparison of contact situation in test rig and tribometer.

\begin{tabular}{lcc}
\hline Parameter & Test rig & Tribometer \\
\hline Contact situation & Conforming contact & Nonconforming contact \\
Relative motion & Sliding & Sliding \\
Max speed & $1000 \mathrm{~mm} / \mathrm{s}$ & $10 \mathrm{~mm} / \mathrm{s}$ \\
Normal load & $1120 \mathrm{~N}$ & $2 \mathrm{~N}$ \\
Max pressure & $130-530 \mathrm{MPa}$ & $160-1080 \mathrm{MPa}$ \\
\hline
\end{tabular}

With this setup, tribometer tests with batch production parts and a contact situation which is described and compared with the test rig situation in Table 2 can be conducted.

The load was chosen to provide a working friction system without vibrations in the friction force sensor signal and to produce a contact pressure which is as close as possible to the real contact situation. To calculate the contact pressure, the equations for the contact of two bodies with arbitrary curved surfaces based on the theory of Hertz were used [11, 12]. With the outer radius of the bush of $5 \mathrm{~mm}$ and the outer radius of the pin of $3,15 \mathrm{~mm}$ and an angle of $90^{\circ}$ between 

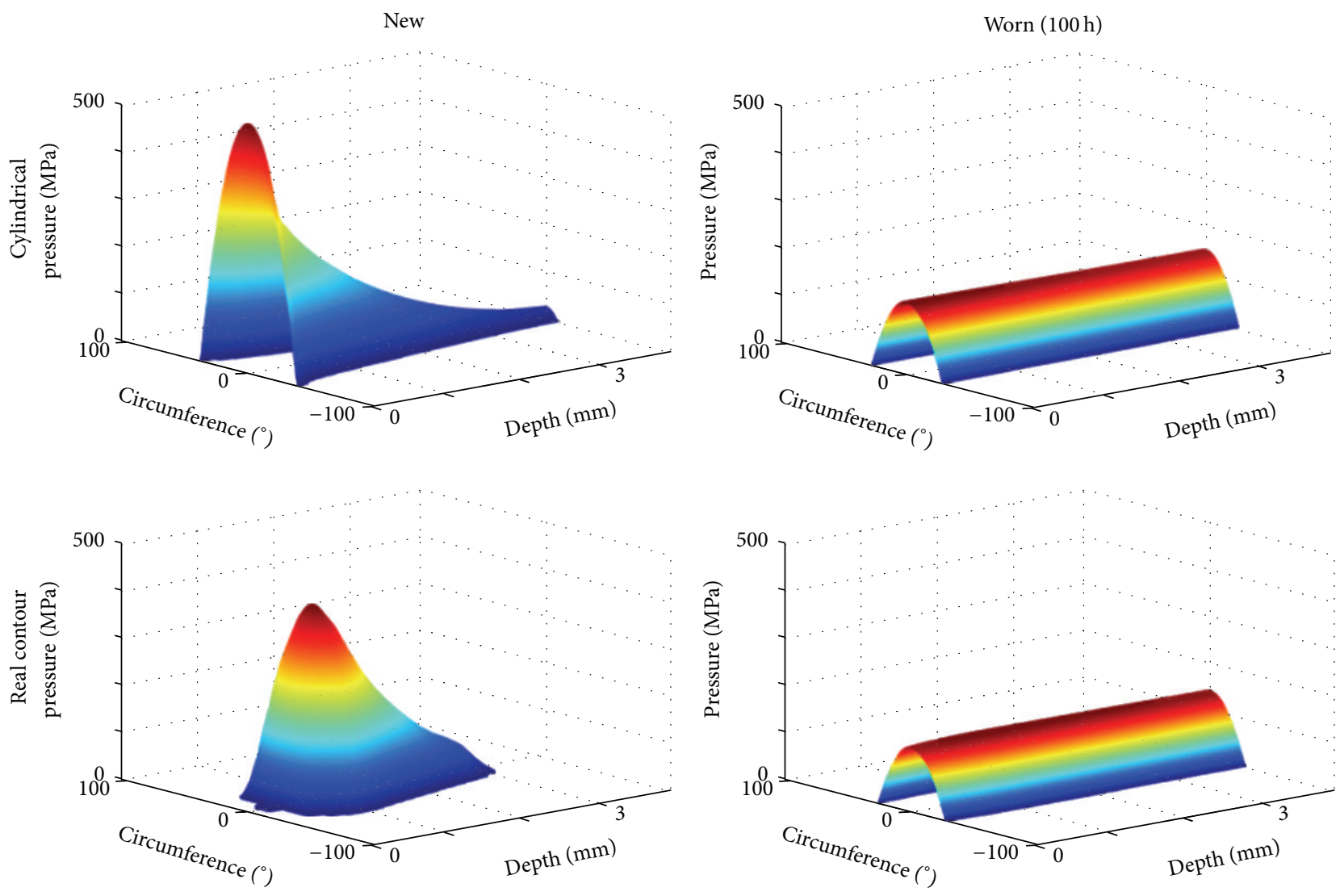

(a)

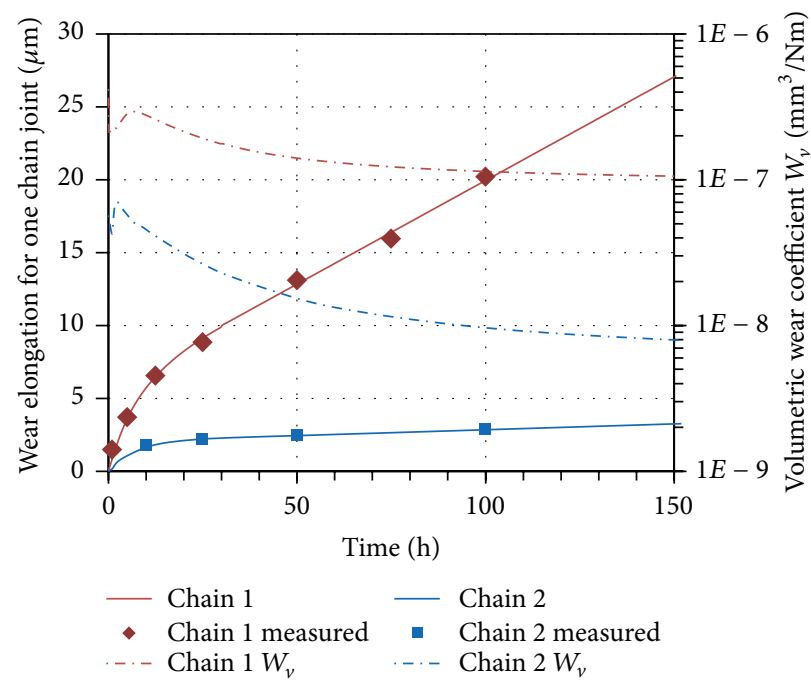

(b)

Figure 6: (a) Pressure distribution for one half of the bush, calculated for a new and worn state and with a cylindrical contour and a contour that was derived from roundness measurement, $1120 \mathrm{~N}$ load [8]; (b) volumetric wear coefficients for two wear elongation curves over the operating time of the chain.

the cylinder axes, the maximum pressure for $2 \mathrm{~N}$ load is $1080 \mathrm{MPa}$ and the average pressure is $720 \mathrm{MPa}$. The calculated contact area is $0,0028 \mathrm{~mm}^{2}$. During the test run, the two bodies are worn which leads to an increased contact area and thus a reduced contact pressure. To estimate the change of the contact pressure, it is assumed that the wear depth on the bush is much higher than on the pin because the wear volume is distributed over a higher area on the pin. With this assumption, an elliptical contact area based on the radii of pin and bush is created which can be calculated from the wear 


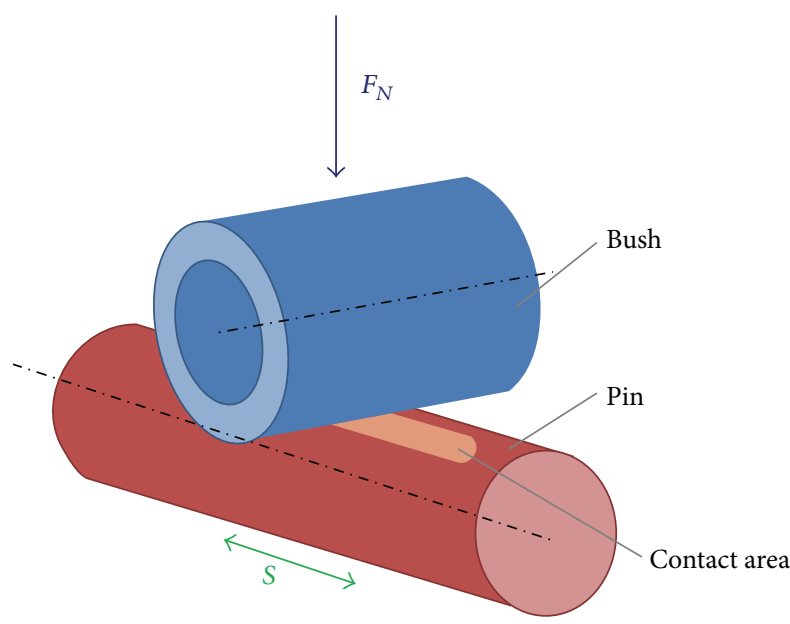

(a)

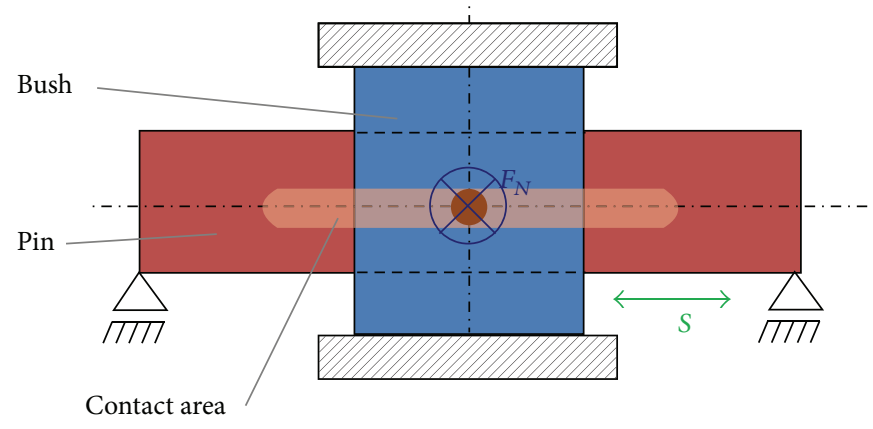

(b)

FIGURE 7: Chain component test setup on tribometer: (a) 3D view of schematic setup; (b) top view of schematic setup.

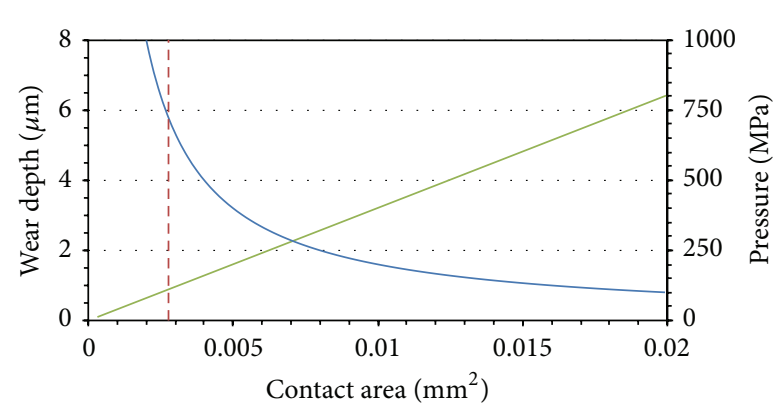

Wear depth
- Pressure
--- Initial contact area

Figure 8: Contact pressure over contact area and wear depth over contact surface.

depth. The results of this calculation are shown in Figure 8. The vertical line shows the initial contact area based on the calculation of the contact of elastic bodies which intersects the pressure curve at the previously calculated $720 \mathrm{MPa}$. With progressing wear, the average contact pressure is reduced to $160 \mathrm{MPa}$ at a wear depth of $4 \mu \mathrm{m}$.

These calculations show that the maximum contact pressure at the beginning of the test run is higher on the tribometer but reduces rapidly with advancing wear which brings it closer to the contact pressure in the chain joint.

To mount the pin and the bush on the tribometer, adapters were developed to position and fix the pin in a heatable oil reservoir on the reciprocating tribometer table (Figure 9(a)) and the inner link which includes the bush in a pin on the tribometer arm (Figure 9(b)).

The used tribometer is a standard pin-on-disc tribometer DTRB 70090 from CSM Instruments. It can be operated in a rotating and a linearly reciprocating setup. The maximum normal load is $10 \mathrm{~N}$. The friction force is measured through a displacement sensor on the flexible tribometer arm. To
TABLE 3: Tribometer test parameters.

\begin{tabular}{ll}
\hline Parameter & Value \\
\hline Normal load & $2 \mathrm{~N}$ \\
\hline Sliding speed & $10 \mathrm{~mm} / \mathrm{s}$ \\
\hline Stroke & $4 \mathrm{~mm}$ \\
\hline Sliding distance & $500 \mathrm{~m}$ \\
\hline & (1) PAO (poly-alpha-olefin) \\
Oil (viscosity acc. to $0 \mathrm{~W}-20)$ & (2) PAO + additive \\
& (3) $\mathrm{PAO}+$ additive $+1 \mathrm{wt} \%$ carbon \\
& black $(\mathrm{CB})$ \\
\hline Oil temperature & $100^{\circ} \mathrm{C}$ \\
\hline
\end{tabular}

calibrate the friction force signal, defined loads are applied to the arm using standard weights and a pulley while the corresponding displacement is measured. This procedure is repeated on a regular basis. Figure 10(a) shows the tribometer equipped with the adapters for pin and bush. The schematic setup is presented in Figure 10(b). The tests were conducted with both components flooded in the oil reservoir.

With this setup, tribometer tests with parameters listed in Table 3 are conducted.

The additive package used in Oil 2 and Oil 3 was based on zinc dialkyldithiophosphate (ZnDTP) and contained extreme pressure (EP), antiwear (AW), corrosion inhibitor (CI), and antioxidant (AO) components. The main elements of ZnDTP are, besides carbon, oxygen, and hydrogen of the organic alkoxy groups, sulfur, phosphorus, and zinc. Calcium bound as carbonate from detergents is also often part of the package. The carbon black was an industrial carbon black with an average primary particle size of $27 \mathrm{~nm}$. It was added to simulate the presence of soot in used engine oils which is an approach that has already been used by different researchers $[13,14]$. With this approach, the differences between varying types of carbon blacks and between carbon black and soot 


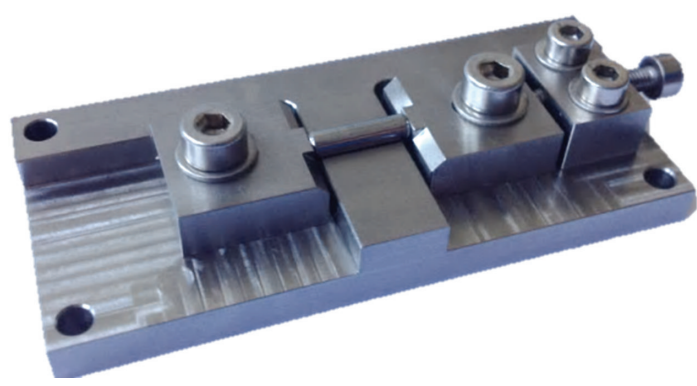

(a)

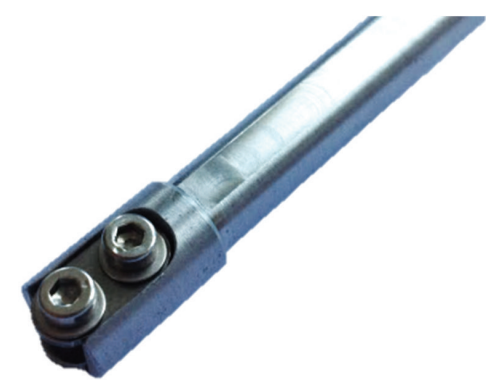

(b)

FIgURE 9: (a) Adapter for pin; (b) adapter for inner link with bush.

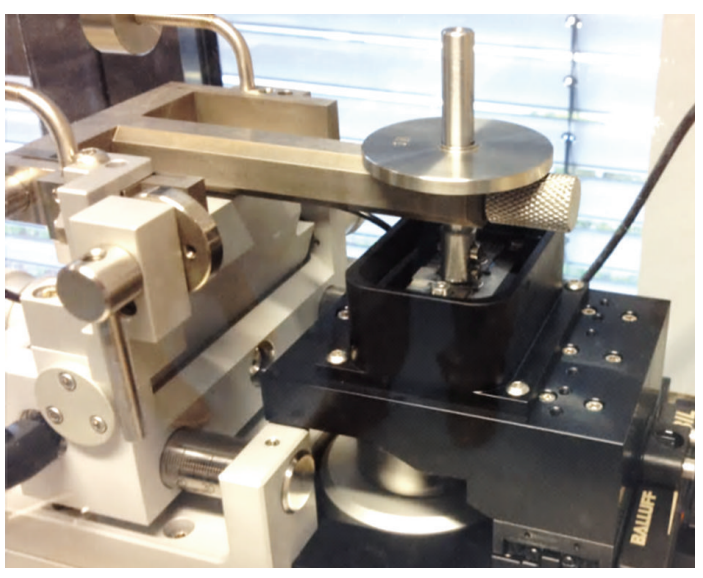

(a)

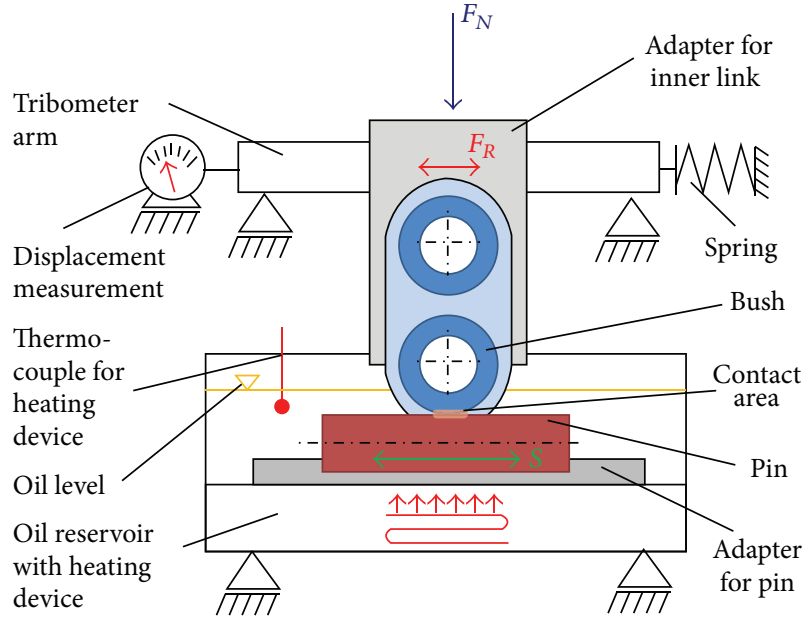

(b)

FIGURE 10: Pin-on-disc tribometer in linearly reciprocating mode with oil reservoir: (a) picture of the tribometer prepared for a test run; (b) schematic representation of the setup including the adapters for pin and bush and the samples.

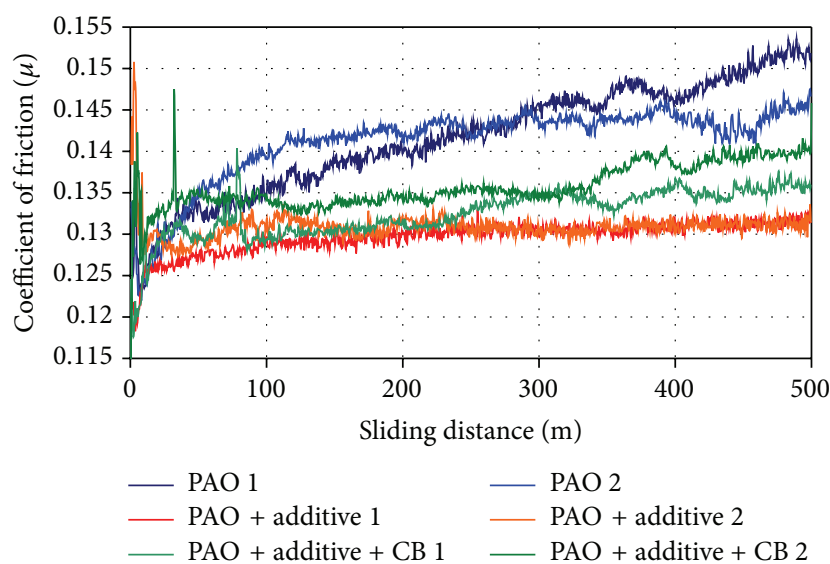

FIGURE 11: Friction coefficient over sliding distance for different types of lubricant.

have to be taken into account when interpreting the results, which is shown by Dilbat et al. [15].

With the above described test parameters and samples, tribometer tests are conducted. The friction coefficient is measured in situ during the test and the wear of pin and bush is investigated after the test by measuring the size of the worn areas and the volume of removed material at the bush. Furthermore surface parameters and the chemical composition of the tribological loaded areas are measured.

\section{Results}

4.1. Friction Coefficient. Figure 11 shows the friction coefficient over the sliding distance for the test runs with different types of lubricant according to Table 3.

These results show that additive reduces the friction coefficient at the end of the test runs from $0,146-0,152$ to 0,131 0,132 . When adding carbon black to the PAO + additive, the friction coefficient is increased to $0,136-0,140$. This behavior has also been observed by Uy et al. $[13,16]$. The resulting friction coefficients at the end of further test runs with the same parameters showed the same trend and were always in the range which is established by Figure 11.

4.2. Wear Volume. To evaluate the wear of the components during the test run, light microscope pictures are taken and 

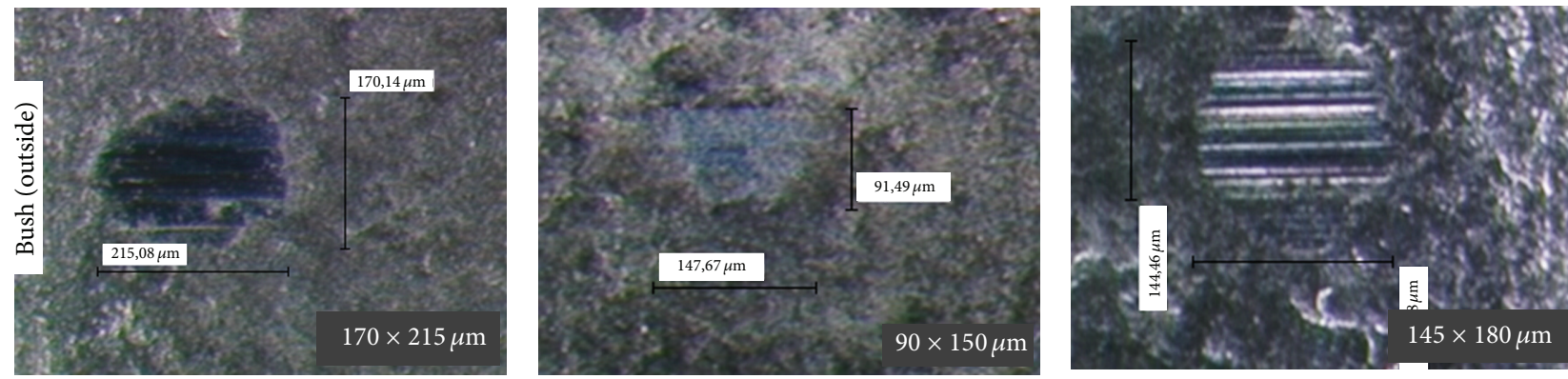

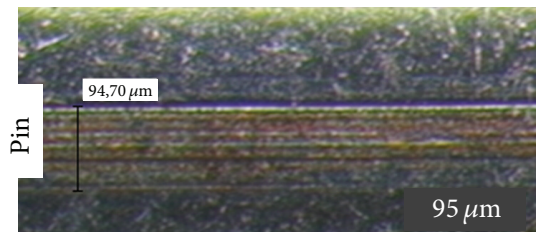

(a) PAO

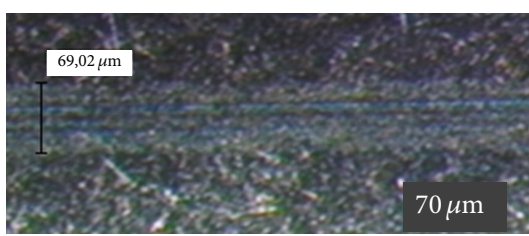

(b) $\mathrm{PAO}+$ additive

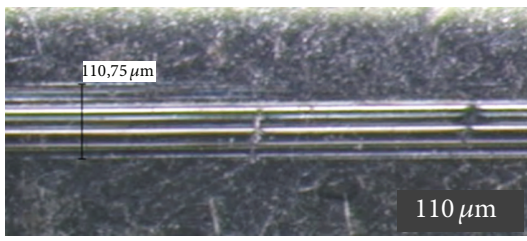

(c) $\mathrm{PAO}+$ additive $+\mathrm{CB}$

FIGURE 12: Light microscope pictures of worn areas on pin and bush with area size on the bush and width of the wear track on the pin.
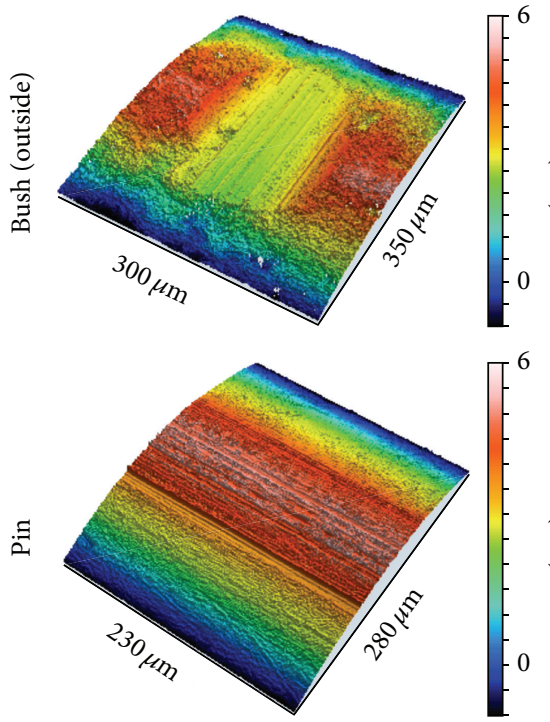

(a) PAO
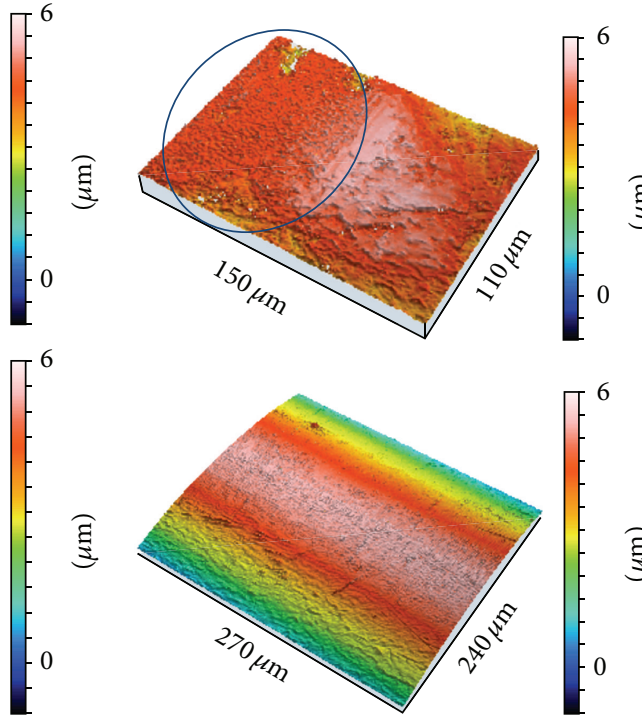

(b) $\mathrm{PAO}+$ additive
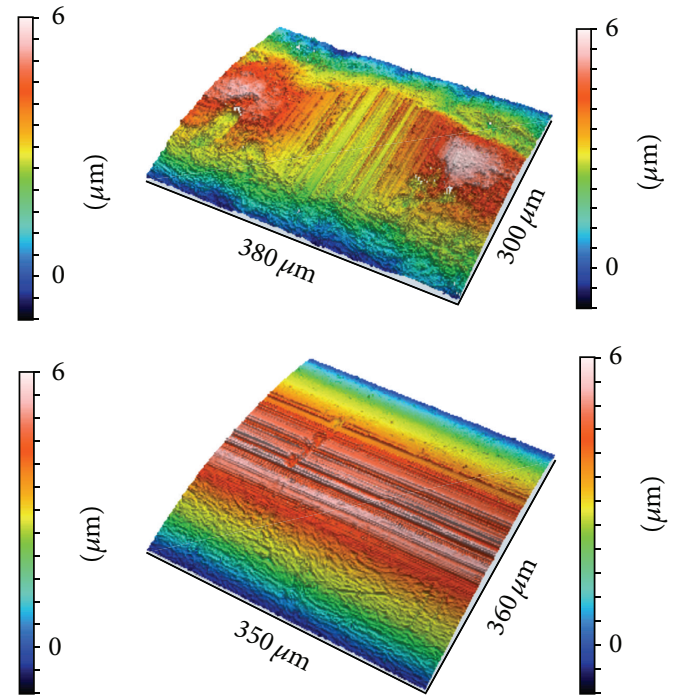

(c) $\mathrm{PAO}+$ additive $+\mathrm{CB}$

FIGURE 13: WLI pictures for pins and bushes with all lubricant types (worn area on bush with PAO + additive is highlighted with a circle).

the size of the worn area on pin and bush is measured and compared, which is shown in Figure 12.

The light microscope pictures show a similar trend as the friction coefficient. The size of the worn area is the highest for the PAO, followed by the PAO + additive + $\mathrm{CB}$. On the samples with $\mathrm{PAO}+$ additive, almost no wear can be observed. These results are confirmed by white light interferometer (WLI) pictures which are shown in Figure 13.

With the 3D surface topography from the WLI, the wear volume can be measured. This is only possible for the bushes because the wear on the pins is distributed over a comparatively large area. Thus, the wear depth is very small. To measure the wear volume on the bushes, the measurement data is filtered and a processing technique which measures the volume below a reference plane is used. This reference plane is created by the height of the surrounding material. The result is shown exemplarily for one bush that was operated with PAO + additive + CB in Figure 14. The volumetric wear coefficient is then calculated with the normal load and the sliding distance. The results are summarized in Table 4.

The volumetric wear coefficients on the tribometer are lower than the ones that were calculated for the test runs on the wear test rig $\left(0,8-20 \times 10^{-8} \mathrm{~mm}^{3} / \mathrm{Nm}\right)$ but they are in the same dimension which is a good result for tribological systems as literature values for various tribological systems are in the area of $5 \times 10^{-10}-1 \times 10^{-8} \mathrm{~mm}^{3} / \mathrm{Nm}[17,18]$. 

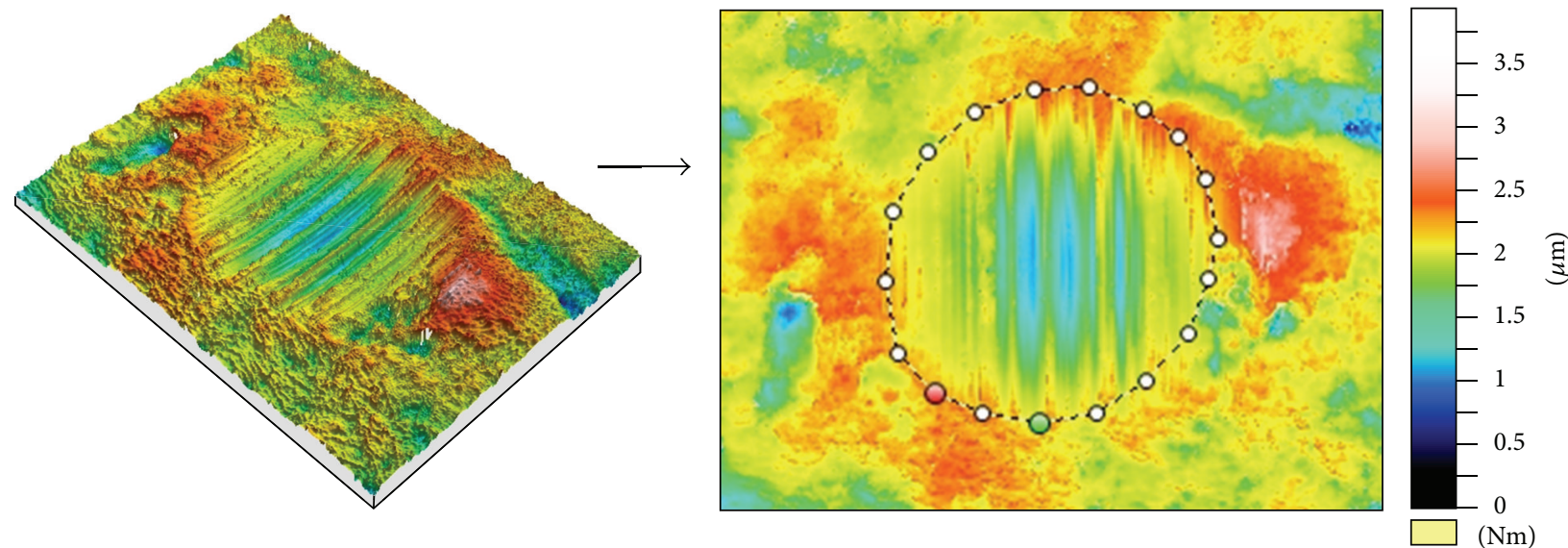

FIGURE 14: Wear volume calculation on the surface of the bush (test run with PAO + additive $+\mathrm{CB}$ ).

TABLE 4: Volumetric wear coefficients $W_{v}$ for the test runs on the tribometer.

\begin{tabular}{lccc}
\hline & PAO & PAO + additive & PAO + additive + CB \\
\hline$W_{v}$ in $\mathrm{mm}^{3} / \mathrm{Nm}$ & $2,50 \times 10^{-8}$ & $\ll 1,00 \times 10^{-8}$ & $1,20 \times 10^{-8}$ \\
\hline
\end{tabular}

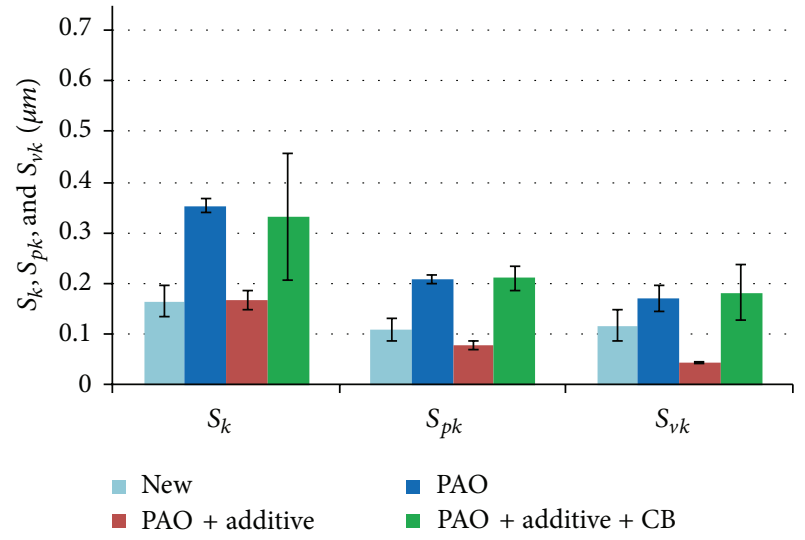

FIGURE 15: Surface parameters derived from the bearing area curve in the worn area of the pins.

Furthermore, the wear of the pins is not taken into account for the calculation of the coefficients so the actual values are expected to be higher.

4.3. Change of Surface Structure. The WLI pictures are also used to measure the bearing area curve in the worn areas of the pins and the bushes. Then, the core roughness depth $S_{k}$, the reduced peak height $S_{p k}$, and the reduced valley depth $S_{v k}$ are derived from the bearing area curve and are compared for the surfaces that resulted from the different lubrication. Figure 15 shows this comparison for the pins and Figure 16 for the bushes.

On the pins, all values are increased with PAO and PAO + additive $+\mathrm{CB}$ while they are reduced or remain the same with PAO + additive (Figure 15). This shows a smoothing of the surfaces with PAO + additive.

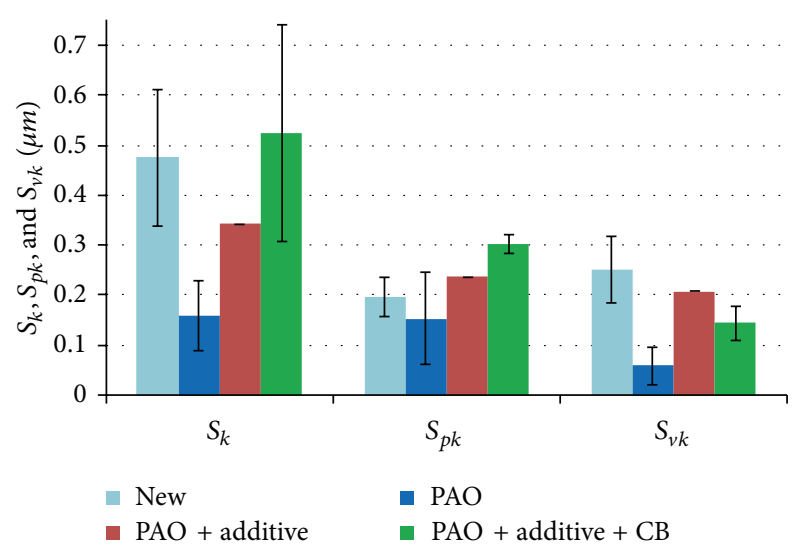

FIGURE 16: Surface parameters derived from the bearing area curve in the worn area of the bushes.

For the bushes, the initial values are much higher and they are reduced with PAO but no distinct change can be observed with $\mathrm{PAO}+$ additive and $\mathrm{PAO}+$ additive $+\mathrm{CB}$ (Figure 16).

4.4. Chemical Composition. To analyse the formation of tribolayers, scanning electron microscopy (SEM) pictures were taken and EDX map measurements were conducted. Prior to this, the samples were cleaned and degreased in an ultrasonic bath with cleaning agents (cyclohexane, acetone, and isopropanol), so that loose, excessive lubricant rests are removed. Only components bound firmly to the surface remained. These components are part of the layer formed under tribological load. Figure 17 shows the SEM pictures and the element maps for the detected elements in the worn areas of the bushes. The information depth of this method is more than $1 \mu \mathrm{m}$. 

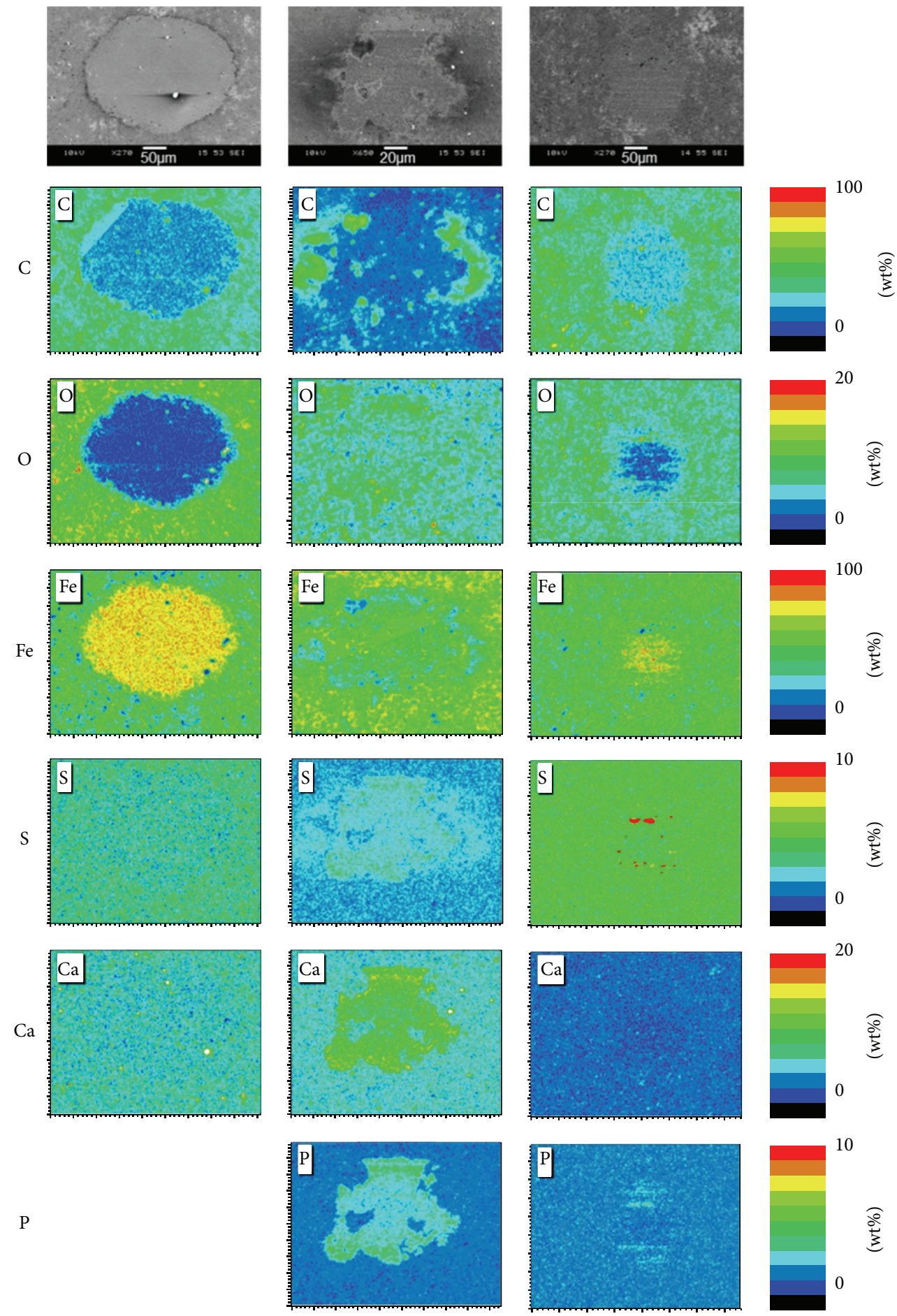

P
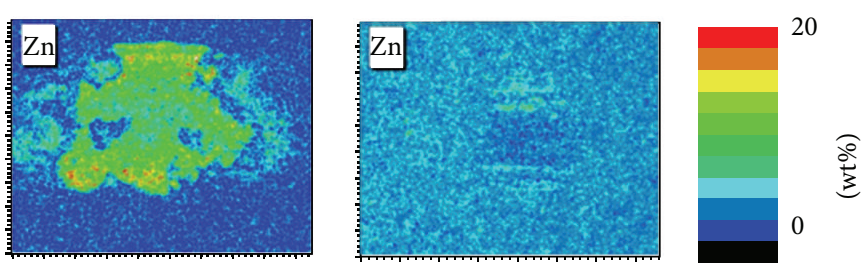

(a) PAO (270x)

(b) PAO + additive (650x)

(c) $\mathrm{PAO}+$ additive $+\mathrm{CB}(270 \mathrm{x})$

FIGURE 17: SE pictures and EDX concentration maps (wt\%) of the worn surface areas on the bushes with the three lubricants. 
For the PAO (Figure 17(a)), the EDX maps show that carbon and oxygen layers were removed and the iron was revealed. No additive typical elements like sulfur, phosphorus, or comparable elements could be detected. A completely different element distribution could be observed on the bush with $\mathrm{PAO}+$ additive (Figure 17(b)). In the worn area, the oxygen concentration is slightly higher. The detection of additive typical elements like sulfur, calcium, phosphorus, and zinc in the worn area is an evidence for the existence of a stable tribolayer formed under influence of the additives exclusively in the tribological stressed areas. The zinc concentration detected by EDX analysis is surprisingly high $(>10 \mathrm{wt} \%)$ regarding a typical layer thickness proposed in literature of $0,5-6 \mathrm{~nm}$ depending on temperature and load [19]. Even the slightly increased oxygen concentrations in this region seem to be caused by additive typical or induced bindings. Additionally in the unworn areas the concentration of carbon and oxygen was much lower and more iron is present, a possible consequence of the detergents included in the additive package. The surface that results from the test runs with $\mathrm{PAO}+$ additive $+\mathrm{CB}$ is comparable to the one with $\mathrm{PAO}$ regarding carbon, oxygen, and iron. As far as tribolayers are concerned, small concentrations of sulfur and zinc can be observed in the borders of the worn areas but not in the center of the contact. To sum up, in all measured elemental distribution pictures (C, O, Fe, S, Ca, P, and $\mathrm{Zn}$ ) the effect of additives, identified as difference between the $\mathrm{PAO}$ and $\mathrm{PAO}$ + additive series, seems to be attenuated by the carbon black.

The reason for this could be that the formed tribolayers were immediately removed due to abrasive effects that were intensified by the existence of carbon black so that no equilibrium state of creation and removal of tribolayers could be reached which is supported by the increased roughness values, especially on the pin. This explanation was also suggested by $\mathrm{Uy}$ et al. $[13,20]$. Another possible explanation is that the efficiency of the additive components was reduced chemically by the carbon black. This effect was already observed with soot, especially with soot from gasoline engines but not with industrial carbon black because of the observed differences in the nanostructure $[21,22]$. Regarding these effects further investigations especially on the properties of the used carbon black are necessary. A possible approach for these analyses is described by La Rocca et al. [23].

\section{Conclusion and Outlook}

In this paper, methods for comparing and transferring results between model tribometer tests and chain test rig investigations are presented. These include the usage of a calculation tool to calculate the volumetric wear coefficient from measured wear elongation curves on chain test rigs. To overcome some drawbacks of the test rig investigations, model tribometer tests are conducted as the samples from these tests are better suited for detailed investigations of surface structure and surface properties like the chemical composition. The friction coefficient and the wear are significantly decreased with the $\mathrm{ZnDTP}$ additive package. When adding carbon black to the oil, which is used to simulate the presence of soot with additive, both friction coefficient and wear are increased to value between pure $\mathrm{PAO}$ and PAO + additive. By using EDX element maps, the formation of tribolayers in the contact area due to the additive is shown and it is asserted that the tribolayer formation was attenuated when carbon black was added to the oil.

The developed methods will be used to investigate the tribological behavior of other material pairings and to measure the performance of surface modifications on pin and bush. Furthermore, the influence of the used carbon black will be compared to the influence of engine soot to better understand the wear mechanisms. In the context of the "Collaborative Research Centre 926," the systematical investigation of different influences especially the contacting surfaces will be continued.

\section{Conflict of Interests}

The authors declare that there is no conflict of interests regarding the publication of this paper.

\section{Acknowledgment}

The authors would like to thank the German Research Foundation (DFG) for the support of the research within the Collaborative Research Centre 926 "Microscale Morphology of Component Surfaces (MICOS)," Subproject nos. B08 and $\mathrm{C} 02$.

\section{References}

[1] T. Fink and H. Bodenstein, "Möglichkeiten der Reibungsreduktion in Kettentrieben," Motortechnische Zeitschrift, vol. 72, no. 7-8, pp. 582-587, 2011.

[2] A. Gummer, D. Sappok, and B. Sauer, "Kettenprüfeinrichtung zur Verschleißuntersuchung von Antriebs- und Steuerketten," Tribologie und Schmierungstechnik, vol. 59, no. 2, pp. 24-29, 2012.

[3] A. Gummer, C. Fábián, and B. Sauer, "Experimental investigation of roller chain wear," in Proceedings of the 18th International Colloquium Tribology, Technische Akademie Esslingen, Ostfildern, Germany, January 2012.

[4] D. Sappok, A. Gummer, and B. Sauer, "Experimental investigation of bush chain wear," in Proceedings of the 8th International Conference on Mechanical Engineering (GÉPÉSZET '12), pp. 472-481, Budapest, Hungary, 2012.

[5] "Gleitlager-Prüfung des tribologischen Verhaltens von Gleitlager-werkstoffen-Teil 1: Prüfung von Lagermetallen," Tech. Rep. DIN ISO 7148-1, Beuth, Berlin, Germany, 2013.

[6] D. Sappok and B. Sauer, "Methoden zur Erfassung der Verschleiß-Messgrößen an Kettenkom-ponenten,” in 54. TribologieFachtagung (GfT) 2013, Göttingen, pp. 70.1-70.11, 2013.

[7] D. Sappok, A. Gummer, and B. Sauer, "Experimental and analytical wear investigations of bush- and roller chain drives," in Proceedings of the 5th World Tribology Congress (WTC '13), Torino, Italy, 2013.

[8] A. Gummer, D. Sappok, and B. Sauer, "Verschleißverhalten von Hülsen- und Rollenketten," Ant Journal, vol. 2013, pp. 10-16, 2013. 
[9] R. G. Bayer, Mechanical Wear Prediction and Prevention, Marcel Dekker, New York, NY, USA, 1994.

[10] A. Gummer, Analytische Untersuchung des Geometrieeinflusses auf das Verschleiß-verhalten von Antriebsketten [Ph.D. thesis], Institute of Machine Elements, Gears, and Transmissions, University of Kaiserslautern, 2013.

[11] K.-H. Grote and J. Feldhusen, Dubbel: Taschenbuch für den Maschinenbau. 23., neu bearbeitete und erweiterte Auflage, Springer, Berlin, Germany, 2011.

[12] S. P. Timosenko and J. N. Goodier, Theory of Elasticity, McGrawHill Kogakusha, Tokyo, Japan, 3rd edition, 1970.

[13] D. Uy, A. E. O’Neill, S. J. Simko, and A. K. Gangopadhyay, "Sootadditive interactions in engine oils," Lubrication Science, vol. 22, no. 1, pp. 19-36, 2010.

[14] E. Hu, X. Hu, T. Liu, L. Fang, K. D. Dearn, and H. Xu, “The role of soot particles in the tribological behavior of engine lubricating oils," Wear, vol. 304, no. 1-2, pp. 152-161, 2013.

[15] M. Dilbat, J. Bölter, W. Mach, and K. Pöhlmann, "Erzeugung von Rußölen mittels eines neu konzipierten Rußgenerators sowie Charakterisierung der erzeugten Rußpartikel," in 53. Tribologie-Fachtagung (GfT) 2012, Göttingen, pp. 36.1-36.11, 2012.

[16] R. Penchaliah, T. J. Harvey, R. J. K. Wood, K. Nelson, and H. E. G. Powrie, "The effects of diesel contaminants on trlbologlcal performance on sliding steel on steel contacts : einfluss von Dieselschadstoffen auf die tribologische Leistung von Stahl-aufStahl-Gleitkontakten," Proceedings of the Institution of Mechanical Engineers, Part J (Journal of Engineering Tribology), vol. 225, no. 8, pp. 779-797, 2011.

[17] K.-H. Habig, Verschleiß und Härte von Werkstoffen, Carl Hanser, München, Germany, 1980.

[18] W. Kollenberg, Technische Keramik-Grundlagen Werkstoffe Verfahrenstechnik, Vulkan, Essen, Germany, 2nd edition, 2009.

[19] R. C. Heuberger, Combinatorial study of the tribochemistry of anti-wear lubricant additives [Dissertation], Eidgenössische Technische Hochschule, ETH Zürich, Zürich, Switzerland, 2007.

[20] H. Bhowmick, S. K. Majumdar, and S. K. Biswas, "Influence of physical structure and chemistry of diesel soot suspended in hexadecane on lubrication of steel-on-steel contact," Wear, vol. 300, no. 1-2, pp. 180-188, 2013.

[21] S. Antusch, M. Dienwiebel, E. Nold, P. Albers, U. Spicher, and M. Scherge, "On the tribochemical action of engine soot," Wear, vol. 269, no. 1-2, pp. 1-12, 2010.

[22] J. Bölter, Auswirkungen von Ruß im Schmieröl von DIDieselmotoren auf das tribologische Verhalten und Tribomutationen von hochbelasteten Motorkomponenten, Karlsruher Institut für Technologie (KIT), Karlsruhe, Germany, 2010.

[23] A. La Rocca, G. Di Liberto, P. J. Shayler, and M. W. Fay, "The nanostructure of soot-in-oil particles and agglomerates from an automotive diesel engine," Tribology International, vol. 61, pp. 80-87, 2013. 

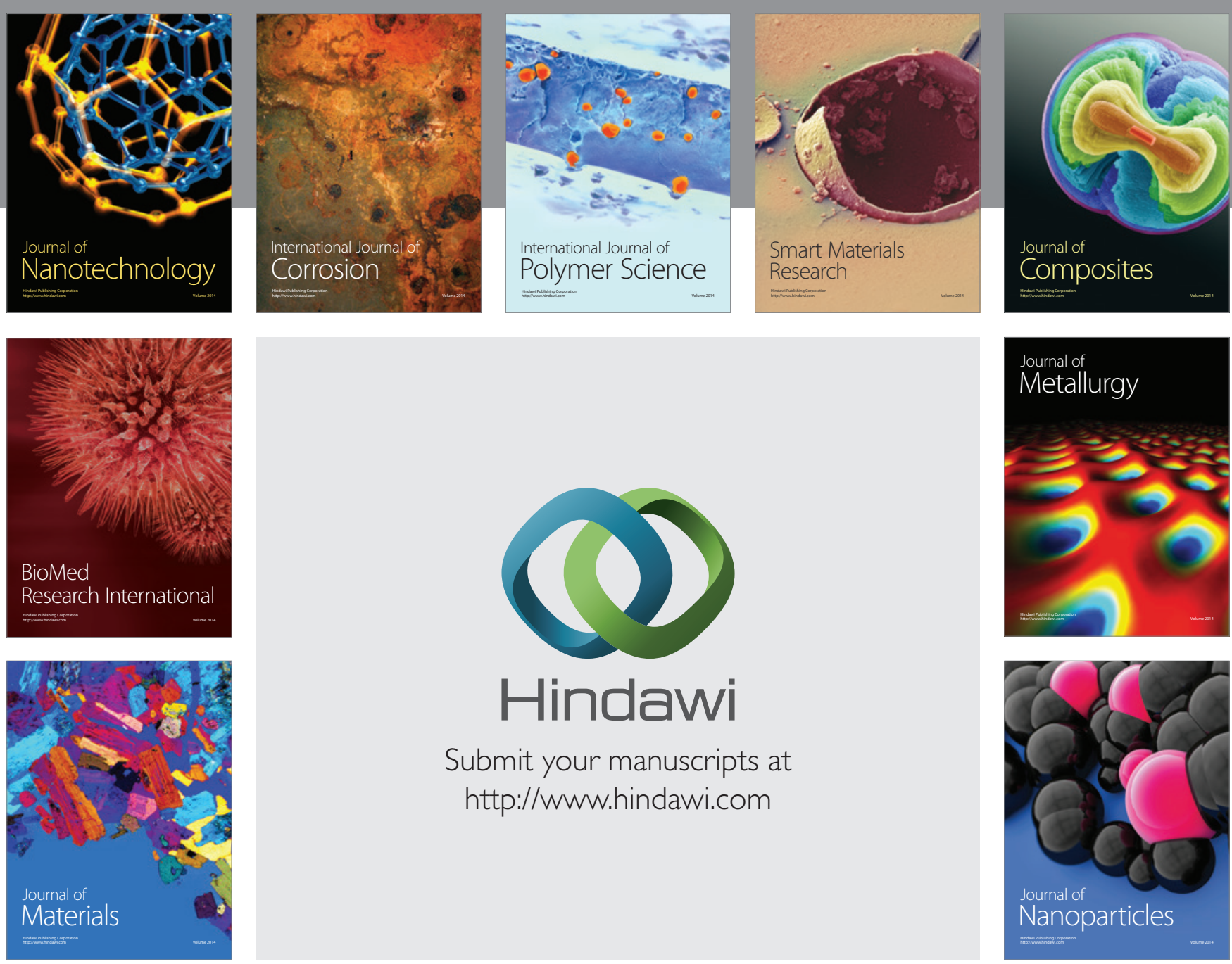

Submit your manuscripts at http://www.hindawi.com
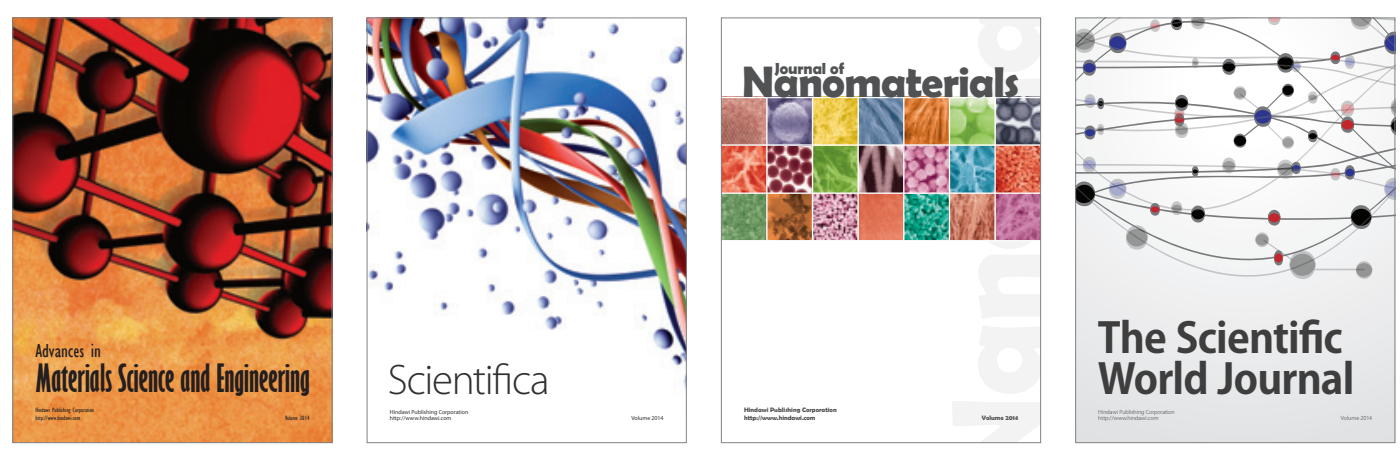

\section{The Scientific World Journal}
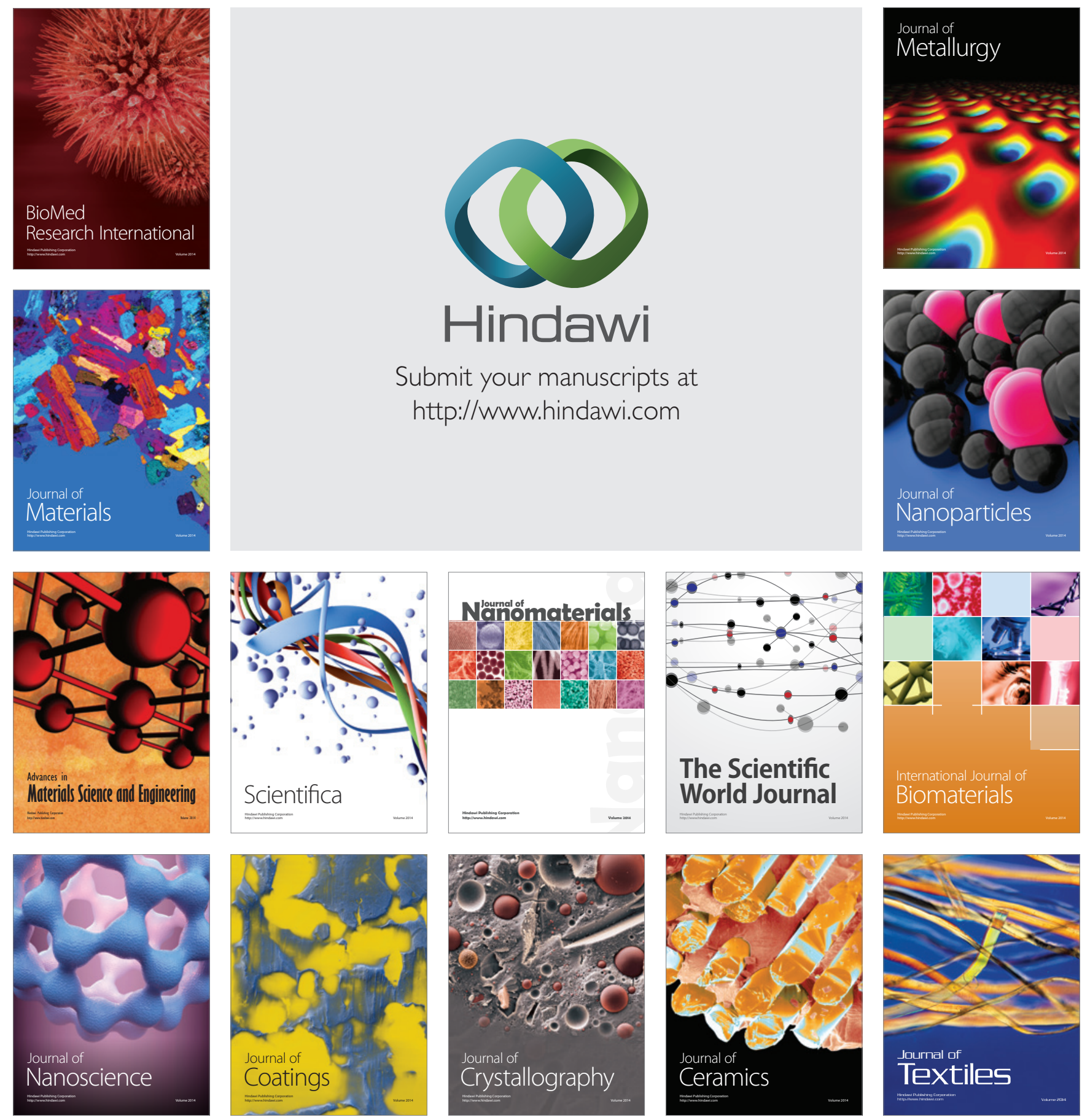